\title{
O corpo negro como tela de inscrição dinâmica nas relações pós-coloniais em Portugal: a Afro como (pre)texto*
}

Celeste Fortes**

\section{Resumo}

No Portugal pós-colonial, as relações entre Portugueses e os Africanos imigrantes continuam a ter no corpo, negro, um "anfitrião" importante. Este artigo procura ensaiar o modo como o corpo pode ser manejado enquanto tela de inscrição dinâmica nas relações inter-étnicas, que mobilizam idiomas de género, classe, etnia, "raça", no contexto pós-colonial português. Usando a revista Afro, lançada em 2008, como pre(texto),procura-se dar conta do modo como esta pode ser lida enquanto projecto que procura contrariar a invisibilidade/visibilidade negativa dos Africanos, pós-coloniais, em Portugal.

Palavras-chave: Portugal Pós-colonial, Africanos Pós-coloniais, Incorporação/Excorporação, Corpo Negro, Gênero.

\footnotetext{
* Recebido para publicação em 6 de agosto de 2012, aceito em 4 de dezembro de 2012. Artigo realizado no âmbito do doutoramento em Antropologia Social e Cultural na Faculdade de Ciências Sociais e Humanas da Universidade Nova de Lisboa, sob orientação da Professora Doutora Susana Trovão e financiado pela Fundação para a Ciência e Tecnologia (2007-2010). Quero agradecer à Professora Susana Trovão, ao José Carlos Gomes dos Anjos (UFRGS/Brasil e Uni-CV, Cabo Verde), ao Lorenzo Bordonaro (CRIA/ISCTE-IUL/Portugal) e à Rita Rainho (M_EIA, Cabo Verde) pelas leituras e pela troca de ideias que muito enriqueceram este artigo.

** Docente e investigadora no Centro de Investigação e Formação em Género e Família na Universidade de Cabo Verde. celeste.fortes@docente.unicv.edu.cv. Investigadora do Centro em Rede de Investigação em Antropologia (CRIA/FCSH UNL/Portugal).
} 
A Afro como (pre)texto

The Black Body as Screen of Inscription of Dynamic Relations in Post-Colonial Portugal: the Afro as (Pre)Text

\begin{abstract}
In post-colonial Portugal, the relations between Portuguese and African immigrants continue to have on the black body an important "host". This article intends to test how the body can be handled while screening the dynamics in inter-ethnic relations, which mobilize languages of gender, class, ethnicity, "race" in the Portuguese post-colonial context.
\end{abstract}

Key Words: Post-colonial Portugal, Post-colonial Africa, Incorporation/ Excorporation, Black Body, Gender. 


\section{Contextualizando os argumentos}

Em Março de 2008, depois de dois meses fora em trabalho de terreno para o meu doutoramento e regressada a Lisboa, fiquei a saber que havia saído uma nova revista (para "Africanos"). Comecei logo a procurar a revista para a comprar, não consegui. Em todos os quiosques por onde passava perguntava se tinham a Afro, todos diziam que tinha já esgotado o $\mathrm{n}^{\circ} 1$ (que havia sido publicada como suplemento da revista VIP).

Em inícios de Abril, quando passava por um quiosque, uma revista que até então não tinha visto nas bancas, atraiu a minha atenção, era a revista Afro (o $n^{0} 2$ ). ${ }^{1}$ Finalmente consegui ter a tal Afro de que muitos falavam. Lembro-me que folhando a revista, vi o slogan que dizia "uma revista deslumbrante, pensada na beleza da mulher de origem africana". Pela capa fiquei a saber que a Impala ${ }^{2}$ é a detentora da revista.

A página on-line da Impala justifica as motivações e os objectivos da criação da Afro como sua nova publicação, através da seguinte mensagem:

A força e o mistério de uma cultura milenar deram o mote à AFRO, a primeira revista portuguesa pensada para a mulher de origem africana. Distribuída em Portugal, Angola $e$ Moçambique, esta publicação reflecte sobre os valores universais da cultura africana $e$ a sua contextualização no século XXI. Saiba o que fazemos chegar até si todos os meses:

Homens e mulheres de origem africana que dão que falar um pouco por todo o Mundo;

Histórias de sucesso em Portugal;

1 Cada número da Afro custa 2,50€; do $1^{\circ}$ ao $5^{\circ}$ há uma edição mensal, do $n^{\circ} 6$ ao 9, a edição passou a ser bimestral, e a partir do n¹0 (2010), a edição tornouse semestral mantendo o mesmo preço.

2 Grupo Impala, com sede em Portugal e distribuição internacional, dono de revistas como Nova Gente, tu7Dias, Maria, Afro e de outros produtos. Ver www.impala.pt 
Moda e beleza, para se manter a par das últimas tendências;

Criações e revelações artísticas, da literatura às artes plásticas;

Sexualidade sem tabus;

Segredos gastronómicos de fazer crescer água na boca. ${ }^{3}$

Servindo-me da revista Afro $^{4}$ como (pre)texto procuro reflectir sobre o ambiente social, político, cultural que se vive no Portugal pós-colonial em torno da imigração africana; e o modo como esse ambiente de (con)vivências e divergências entre Africanos e Portugueses é muita vez marcado pela invisibilidade e/ou visibilidade negativa dos primeiros no espaço público português, apesar de haver um discurso recorrente de que a história de descobrimentos e expansão dotou os Portugueses de um modo específico de estar no Mundo (Castelo, 1999), que nas relações pós-coloniais se traduz num modo português de receber o Mundo Africano pós-colonial afirmando a não existência de racismo nessas relações. ${ }^{5}$

A publicação da revista Afro pode ser lida a partir desse contexto de (con)vivência e divergências quotidianas e enquanto um projecto que procura tornar os Africanos positivamente visíveis. Considerando esse projecto, particularizo minha reflexão para os elementos mais visíveis quando folheamos a revista $n^{\circ} 4$ : "O Corpo Negro"/"Corpo Africano". 6

3 Disponível em: <http://www.impala.pt/html/revista_q1id_object_3D19125 __22_q30_q41_q5.htm> Acesso em:_27 de Março de $200 \overline{8}$.

4 Ao longo de todo o artigo centralizarei as reflexões, sobretudo, no $n^{\circ} 4$ da revista Afro.

5 Considero que essas reflexões podem ser transversais a qualquer corpo estrangeiro/imigrante, contudo devo realçar que as minhas reflexões resultam ou partem do meu posicionamento e lugar de enunciação (Bhabha, 1994) enquanto mulher cabo-verdiana, africana, antropóloga, que vive a experiência de ser imigrante em Lisboa (Portugal).

6 Opto, neste texto, por usar o termo Africano(s) como é usado na revista, estando ciente dos manejos situacionais que dele são feitos por aqueles que se definem identitariamenente enquanto Africanos. Nesse contexto, a ligação com a 
Ensaiarei algumas questões em torno do corpo enquanto tela de inscrição dinâmica nas relações inter-étnicas que mobiliza idiomas de género, classe, etnia e "raça". Para dar conta do modo como nas relações entre Africanos (imigrantes e/ou filhos de imigrantes) e Portugueses (autóctones/do contexto de acolhimento) no contexto de relações pós-coloniais, o corpo negro é manejado para estabelecer, criar, apresentar e representar pertenças.

Quais as razões que justificam a existência de uma revista direccionada para os Africanos em Portugal, particularmente para as mulheres de origem africana? Ou mais importante ainda, por quê os negros não aparecem com mais frequência nas outras revistas, com os mesmos propósitos da Afro?

A leitura do contexto actual das relações pós-coloniais entre Africanos e Portugueses não pode ser feita sem uma revisitação da história colonial portuguesa que analise, ainda que brevemente, o modo como o corpo esteve sempre presente nas relações coloniais entre Africanos e Portugueses.

Essa revisitação das narrativas produzidas em torno do corpo negro durante o período colonial se justifica pelas possíveis continuidades das imagens que muitos podem ainda ter sobre o corpo negro/africano, mas também pelo facto de haver uma clara reconfiguração e revalorização dessas imagens por parte sobretudo, dos Africanos.

\section{Revisitando a história: o corpo nas relações coloniais entre Portugueses e Africanos}

As relações entre Portugal e os seus imigrantes, póscoloniais, não podem ser escamoteadas sem um análise histórica sobre o modo como Portugal se relacionava, durante o período colonial, com os seus colonizados. Como sugere Miguel Vale de Almeida,

cor da pele é uma das formas mais recorrentes de se afirmar ou auto-afirmar enquanto africano. 
A revisitação das narrativas colónias portuguesas - do estado, dos saberes, das artes, das pessoas - é um empreendimento fundamental para compreender como se configura a comunidade de sujeitos e cidadãos debaixo da República Portuguesa hoje (Almeida, 2006:367).

É possível encontrar essas preocupações nos trabalhos de vários investigadores Portugueses e não só, que também partilham da sugestão de Miguel Vale de Almeida.

Clara Carvalho (2008) tem analisado o modo como as narrativas coloniais produzidas em torno do corpo e das imagens corporais foram um importante alicerce para as relações que então se mantinham entre brancos e negros nas antigas colónias portuguesas (Carvalho, 2008). Isto é, o corpo esteve sempre presente nas relações entre brancos, europeus (colonizadores) e negros, Africanos (colonizados).

Trabalhando sobre as imagens de arquivo da Guiné-Bissau, a investigadora mostra que nessas imagens fotográficas, produzidas no período colonial, é muito visível a exposição do corpo de homens e de mulheres Africanas, que salienta a nudez sobretudo de mulheres, sendo a "exposição dos seios" o mais recorrente.

Partindo do ambiente social, cultural e político da época, hoje considerado um ambiente conservador, a máquina colonial manejava essa "nudez", transmitindo aos Portugueses da metrópole, representações dos colonizados enquanto seres primitivos e não civilizados, legitimando, desse modo, o projecto $e$ a ideologia coloniais Portugueses (Carvalho, 2008).

A exposição das imagens fotográficas servia assim a propósitos muito mais vastos do que o simples acto de fotografar os "encontros" com os Outros. O exercício do poder sobre o Outro pela exposição da sua suposta fragilidade e primitivismo pelo seu corpo nu, através do acto de fotografar é também, como afirma Carvalho, uma das formas de analisar a representação do género durante o período colonial, particularmente a representação da mulher negra (guineense) pela máquina colonial, 
pois que quem fotografa, pode-se imaginar, é o homem branco (id.ib.). Mas como conclui a autora

Neste processo a representação fotográfica da figura feminina representou, de forma relativamente constante ao longo do Estado Novo, uma sublimação do inatingível, uma encenação visual do controlo e da posse sempre adiados (Carvalho, 2008:172). ${ }^{7}$

Como mais adiante se verá, as imagens do corpo negro, sobretudo feminino, enquanto corpo desejado pelo seu exotismo e sensualidade continuam presentes no modo como Africanos $e$ particularmente Portugueses, olham para as mulheres Africanas, nas relações quotidianas em Portugal.

Do mesmo modo, o mito de que os homens negros são "mais dotados" e que por isso "levam vantagem no sexo" continua a figurar nas narrativas identitárias dos Africanos, sobretudo em contextos de competição identitária com Portugueses, por exemplo.

\section{O corpo negro nas relações inter-étnicas no contexto pós- colonial português: A Afro como (pre)texto}

No correio de leitores do $\mathrm{n}^{\circ} 4$ da revista Afro, assim se manifestou uma leitora:

Tenho 33 anos, sou natural de Moçambique e a viver em Portugal desde o segundo ano de vida. Para mim é um orgulho existir uma revista direccionada para os Africanos, toda a sua cultura, beleza e carisma. Sou consumidora das revistas americanas e brasileiras e agora já existe uma em

\footnotetext{
7 Não cabendo aqui uma reflexão comparativa da colonização Portuguesa e das outras potências colonizadoras, no que toca ao modo como o corpo negro do colonizado foi representado e apresentado nas metrópoles colónias com visões similares, no que toca ao seu exotismo, hipersexualidade, primitivismo, etc, sugiro a leitura de: McClintock (1995), Stoler (1995) e de Hyam (1990).
} 
Portugal. Torço por esta revista; que conquiste o lugar para o orgulho dos Africanos, vou comprá-la todos os meses. Leitora da Revista Afro (Afro, 4).

A revisitação das narrativas coloniais em torno do corpo negro, particularmente do corpo negro feminino (com as devidas ressalvas temporais e espaciais em que aconteceram) é importante para que hoje se reflicta, através da Afro enquanto instrumentos de comunicação intercultural, o modo como o corpo negro e as imagens que dele quotidianamente se criam, também está presente nas relações inter-étnicas entre os Africanos e os Portugueses, no presente contexto, pós-colonial.

Depois de ter comprado a revista, partilhei com alguns colegas, sobretudo com alguns Africanos, as minhas reflexões sobre a revista Afro e sobre as questões do corpo negro abordados pelo seu $\mathrm{n}^{\circ} 4$, procurando escutar a avaliação que fazem da pertinência de se publicar uma revista Afro em Portugal. As opiniões dividiram-se entre aqueles que se posicionavam contra a sua existência e outros que não viam qualquer relevância na sua criação. Mas apesar dessas opiniões antagónicas não deixaram de levantar questões que merecem atenção e reflexão profunda: por que surge uma revista exclusiva dedicada aos Africanos, e particularmente à mulher negra de origem africana? E a esta questão se junta outra (que penso ser mais abrangente): por que nas outras revistas que semanalmente se comercializam em Portugal (sobre a tutela da mesma empresa ou de outras) não aparecem com mais frequência, os negros?

No Portugal de hoje, que a par de país de emigração também se tornou num país de imigrantes, provenientes sobretudo das ex-colónias portuguesas (Almeida, 2004b, 2006; Ribeiro, 2004; Sanches, 2006), a questão da invisibilidade dos negros no espaço público português tem sido um dos temas centrais quando se fala do modo português de receber os imigrantes (Almeida, 2000, 2006; Sanches, 2006; Mata, 2006; Cunha et alii, 2006). 
Essa invisibilidade, segundo esses investigadores, se faz acompanhar de uma visibilidade negativa dos imigrantes (refirome sobretudo aos imigrantes Africanos) e faz despoletar críticas à comunicação social portuguesa por, na maioria das vezes, transmitir notícias sobre os Africanos em Portugal sobre um ponto de vista negativizado e estereotipado. ${ }^{8}$

Pensar Portugal hoje, na sua condição pós-colonial, não pode ser empreendido sem um trabalho de revisitação da sua história, já que ela continua a ser marcada profundamente pelo seu passado colonial. O regresso ao passado e a reflexão do presente com olhos no passado marcam também esta minha proposta de trabalho, através de "algo" que muitas vezes é descurado do debate: o corpo, focando a aproximação e distanciamento entre corpo negro (Africano) e corpo branco (Português).

A presença desses Outros, agora não colonizados mas imigrantes, possuidores de outras nacionalidades, são o resultado "das sequelas do passado, momentos incontornáveis que revelam a complexidade, se não a fatalidade, dos laços construídos ao longo de toda a história da modernidade" (Sanches, 2006:8).

Mas esses Outros, como também afirma Sanches (2006), são aqueles

que a homogeneidade da nação e dos seus símbolos insiste em não querer pensar e reconhecer, a não ser assimilando ou tolerando vagamente (...) o que, muitas vezes, se afigura finalmente intolerável (Sanches, 2006:8).

Se a história ainda é marcante, ela não pode ser "travada", sobretudo porque os laços coloniais foram "cortados" muito recentemente, para serem edificados agora, com outros idiomas e dinâmicas.

8 O episódio flagrante do modo como as notícias acerca dos imigrantes são tratados na comunicação social portuguesa é o caso do arrastão que foi noticiado como acontecimento do dia (10 de Outubro de 2005) e porque não do ano, mas que não aconteceu. 
A expressão mais visível é a criação da lusofonia, da Comunidade de Países de Língua Portuguesa. Contudo, as relações entre imigrantes e os Portugueses não são construídas à base de premissas de "irmãos lusófonos", apesar da partilha de uma língua comum - o Português, língua do antigo colonizador. $\mathrm{O}$ modo português de receber o mundo pós-colonial, que bate às suas portas, não é de um anfitrião que recebe amistosamente amigos de longa data na sua casa. Muitos não se sentem em casa durante o período de vida em Portugal, por manifestarem sentimentos de que a sociedade portuguesa é racista, ainda que não o assuma.

Não sendo um lugar-comum, sobretudo na vivência quotidiana, são vários aqueles que defendem que por mais que se tente, sobretudo nos corredores políticos, a lusofonia não apaga a história dos encontros coloniais que se viveu em África (Margarido, 2000).

Vale de Almeida prefere inclusive substituir a ideia de que houve encontros pelo facto de terem sido confrontos e que prevalecem até hoje, porque

quando os Africanos pós-coloniais migram para Portugal, migram para ocupar posições de classe que lhes retiram toda e qualquer mais-valia enquanto exóticos localizados. Ocupam agora as margens do centro, nas relações de produção, como na geografia social (Almeida, 2006:364).

A geografia social a que Almeida se refere é a combinatória entre a posição de classe baixa ocupada por muitos imigrantes $e$ os reflexos espaciais dessa ocupação de classe, isto é, em termos espaciais são cartografados no facto de muitos viverem em bairros sociais. Francisco Carvalho (2006) trabalhando precisamente esta combinatória entre espaços da cidade, presença ou ausência de negros e o turismo e recorrendo à análise de guias turísticos que promovem a cidade de Lisboa, aos Portugueses e a estrangeiros, 
afirma que "os negros não são incluídos na imagem dominante de Lisboa" (Carvalho, 2006:87).

Carvalho refere que essa ausência é visível na promoção que os guias turísticos fazem da Lisboa Alfacinha, que denota uma visão própria da construção da ideia de nação portuguesa (id.ib.). Contudo existem também guias turísticos que procuram contrariar essa ausência dos negros, ao promoverem espaços onde o encontro com uma Lisboa Africana é possível, comprovando a existência secular dos negros na vida quotidiana de Lisboa. Como afirma Carvalho, esses guias que promovem a Lisboa Africana recorrem à cultura, nesse caso africana, enquanto idioma identitário, para "passar uma imagem positiva do africano, afastando os supostos motivos de exclusão e criando, deste modo, a possibilidade de renegociação da sua pertença à sociedade lisboeta" (id.ib.:94).

No contexto das relações entre Portugueses e Africanos, a revista Afro parece-me ser um outro meio para reflectir sobre projectos individuais e colectivos que procuram uma visibilidade positiva dos Africanos no espaço público português, nesse caso através do corpo, das suas potencialidades e performances.

Esses projectos podem ser analisados como um desafio/resistência à construção da identidade Portuguesa, que se confronta em permanência com projectos que procuram construir uma identidade Africana (Mata, 2006; Carvalho, 2006). Se estes desafiam a construção de uma imagem de nação Portuguesa, também podem ser pensados enquanto projectos que procuram desterritorializar essa positivização dos Africanos. ${ }^{9}$

Não deixa de ser assim interessante notar e reflectir sobre o facto de o número inaugural da Afro trazer em destaque de capa a actriz Tais Araújo, uma referência negra Brasileira, e não uma referência negra Portuguesa. Do mesmo modo ressalta-se o facto

9 Merece também reflexão sobre o inverso, isto é, nos espaços geográficos descolonizados, Africanos, o que acontece ao corpo Português, em especial às mulheres portuguesas "brancas"? 
A Afro como (pre)texto

de em todos os seus números a revista fazer referência a negros que "triunfaram" noutros países, sobretudo Estados Unidos de América e Inglaterra.

\begin{abstract}
África, terra de uma beleza singular, de uma mistura de cores e aromas, de uma vida selvagem única, está presente um pouco em todos os cantos do Mundo e os seus descendentes transportam consigo a magia que caracteriza um continente apaixonante (Afro, 4:102).
\end{abstract}

Se no encontro/confronto histórico entre colonizados $e$ colonizadores, o corpo esteve presente, também com a migração daqueles para Portugal, ele está sempre presente, contudo, aqui e agora, o corpo negro tem sido revalorizado como mediador activo nas relações reconfiguradas, entre Africanos e Portugueses.

A migração enquanto encontro/confronto cultural introduz a possibilidade de adoptarmos uma outra perspectiva no estudo das relações daí decorrentes. Tal mudança de paradigma situa-se sobretudo no nível das reapropriações de discursos e narrativas que se, num outro contexto podiam ser lidos enquanto narrativas que veiculavam imagens negativas, no contexto das relações póscoloniais podem ser manejados de uma forma positiva, particularmente por Africanos.

Como defende Hallan e Street

Sem negar as desigualdades de poder ou as tendências homogeneizantes dos processos globais, deve ser dada atenção às diferentes formas de incorporação, resistência $e$ reinvenção das representações dominantes (Hallan e V. Street, 2000:5). ${ }^{10}$

\footnotetext{
10 "Without denying inequalities of power or the homogenising tendencies of global processes, attention needs to be paid to the ways in which dominant representations are incorporated, resisted and reinvented" (Hallan and V. Street, 2000:5) [tradução da autora]
} 
Os protagonistas desses encontros/confrontos partilham quotidianamente palcos relacionais, dinamizados por jogos de representações mútuas (Goffman, 1993), verdades parciais (Clifford, 1988), próprias de dinâmicas de relações inter-étnicas e transculturais, nas quais pensar e representar o "nós" depende das imagens do "nós" que queremos transmitir aos outros e a nós mesmos, do modo como construímos e veiculamos imagens dos Outros.

Como é manejado e reconfigurado esse corpo pós-colonial?

Os manejos situacionais do corpo nas relações entre Africanos e Portugueses são o resultado dessa reinvenção de imagens que possibilitam estratégias de resistência contra quaisquer projectos de continuação dos discursos de poder veiculados, através do corpo, durante o período colonial.

Notamos por um lado, a ocorrência de dinâmicas de incorporação de imagens negativas, definida enquanto:

interiorização não verbal, inconsciente, mimética, automática, de certas disposições de desigualdade e de poder: mas não só como interiorização - também como reprodutor dessas realidades, seu confirmador constante pelo simples facto de estar lá, de aparecer, de ser (Almeida, 2004:30).

Por outro lado, veremos que a par dessa incorporação, existem também estratégias de excorporação (Ferreira, 2007) de imagens positivas, como sendo o mais prevalecente no projecto de visibilidade positiva dos Africanos em Portugal.

A centralidade do corpo nas dinâmicas identitárias e no quotidiano das relações sociais é defendida por vários autores (Featherstone e Turner 1995, Ferreira, 2006, 2007, Mafessoli, 1990, Ribeiro, 2003, Shilling, 1991, 1993, 1997a, 1997b, 2001, etc) procurando retirar a posição marginal que o corpo ocupava nas ciências sociais.

Shilling $(1991,1993,1997 a, 1997 b, 2001)$ trabalha a partir do conceito de capital físico de Pierre Bourdieu, referindo-se à análise 
que este faz do capital físico enquanto constituinte do capital cultural, defende que o corpo é tão central nas relações sociais, na produção e manutenção de status e diferenças, que pelo corpo se produz capitais económicos e culturais;por conseguinte deve ser analisado como um capital em si e não como subdivisão do capital cultural (Shilling apud Bourdieu, 1991:654).

E é nessa perspectiva do corpo enquanto capital físico, que reside uma das maiores viragens na análise do corpo nas ciências sociais. Para Shilling, a forma mais abrangente de olhar e analisar o corpo é aquela que o contempla

Como um objecto material localizado na natureza; mas que está sujeito a mudança social... não apenas construído por relações sociais, elas também entram na construção destas relações (Shilling, 1991:664). ${ }^{11}$

O corpo, até aqui visto como naturalizado, obriga-nos a olhar para ele enquanto lugar dinâmico, que exerce um papel simbólico e de agencialidade nas relações quotidianas (Reischer e Koo, 2004).

Featherstone e Turner (1995), Reicher e Koo (2004) ajudamnos a reflectir sobre essa duplicidade de papéis do corpo, enquanto um "corpo simbólico" e enquanto um "corpo agente", sendo que

a primeira e mais prevalecente perspectiva incide sobre a natureza representacional ou simbólica do corpo como condutor de significados sociais enquanto a segunda destaca o papel do corpo como um agente participante activo no mundo social (Reicher e Koo, 2004:298). ${ }^{12}$

\footnotetext{
11 "as a material object located in nature; but subject to social change....not just constructed by social relationships, they also enter into the construction of these relationships" (Shilling, 1991:664). [tradução da autora].

12 "the first and more prevalent perspective focuses on the representational or symbolic nature of the body as conduit of social meanings whereas the second
} 
Este artigo procura explorar esse duplo lugar que o corpo ocupa nas relações pós-coloniais em Portugal. O corpo negro, enquanto capital físico ganha, no quadro dessas relações, um papel simbólico e dinâmico servindo-se de mediador entre o Nós (Africanos) e os Outros (Portugueses, etc). Constitui um desafio enriquecedor pensar no que é feito com o corpo negro nas relações quotidianas e o que o próprio corpo negro faz nestas mesmas relações (Featherstone e Turner, 1995), o modo como o corpo negro se manifesta e o modo como ele próprio é um manifesto (Almeida, 2004).

Pelo corpo negro, mediador das relações, se pode apreender os significados sociais atribuídos ao ser-se negro, isto é, há como que instantaneamente uma inter-relação, que muitas vezes produz juízos de valores entre o corpo que tem cor e uma pertença identitária. Como afirma Ferreira (2007)

o corpo tem sempre, em potência, essa dupla capacidade de se revelar lugar de conformação e confrontação social, de controlo e resistência, de autoridade e subversão, de contenção e excesso, de disciplina e transgressão de poder $e$ evasão, de alinhamento e oposição, de reprodução $e$ inovação de dominação e agenciamento, de subordinação e emancipação (Ferreira, 2007:293).

$\mathrm{O} \mathrm{n}^{\circ} 4$ da revista Afro abre com a seguinte mensagem da editora Paula Machava Seibert:

Por mais que possamos escrever sobre o calor e a sedução da pele negra, ficamos sempre aquém daquilo que pensamos. Há muito que falar sobre a nossa identidade...dizem que a mulher africana é mais quente e o homem negro é mais dotado. Segundo alguns mitos, os Africanos são bem avantajados e óptimos amantes. Os

highlights the role of the body as an active participant agent in the social world" (Reicher e Koo, 2004:298) [tradução da autora]. 
homens são mais viris e as mulheres mais sensuais. A pura verdade é que temos a nossa maneira própria de nos expressarmos. Quem conseguir interpretar este tipo de linguagem pode ler o que nos vem na alma. Temos o ritmo no sangue, o escaldante calor no corpo $e$ a sensualidade na pele (Afro, 4:1).

Pela Afro se pode constatar o modo como o corpo, as imagens e performances corporais são centrais na definição situacional e dialéctica da "identidade Africana"; assim como nos guias turísticos analisados por Francisco Carvalho, na Afro, particularmente no $\mathrm{n}^{\circ} 4$, os nossos olhares são orientados pelas imagens corporais que nos conduz para interpretações, também elas resultados das nossas experiências quotidianas e das nossas relações com os nossos "outros".

Essas imagens, que se fazem acompanhar de narrativas valorizantes dos negros, têm poder de representação identitária do "nós" Africanos, em que o corpo adquire um papel fundamental. Partilho da perspectiva, entre outros, de Stuart Hall (1997) para quem "sinais e imagens visuais, mesmo quando têm semelhanças com as coisas a que se referem, continuam a ser sinais: carregam significados e portanto, têm de ser interpretadas" (Hall, 1997:19). ${ }^{13}$

A exposição de corpos negros na Afro remete-nos também para a possibilidade de analisarmos o modo como são produzidas $e$ veiculadas narrativas em torno da feminilidade $e$ de masculinidade negra, (das dinâmicas de representações de género), sendo que nesses casos os códigos apresentativos (Ribeiro, 2003:206) são traços corporais que têm a ver com tamanho do pénis, das mamas, do rabo, o "rebolar das ancas", que procuram transmitir uma sensualidade e exotismo definidores, segundo essas narrativas, da "identidade africana". Tendo em conta que

\footnotetext{
13 "Visual signs and images, even when they bear a close resemblance to the things to which they refer, are still signs: they carry meaning and thus have to be interpreted" (Hall, 1997:19). [tradução da autora].
} 
um corpo exposto emite sempre um conjunto de indícios o vestuário, a postura, a mímica e o olhar, os gestos $e$ movimentos - que desafiam qualquer observador, manifestando-lhe uma intencionalidade, dirigindo-lhe um apelo, sugerindo-lhe uma interpretação ou um juízo estético (Ribeiro, 2003:65).

Tais códigos apresentativos são manejados enquanto traços valorizantes $e$ valorizadores num projecto de competição identitária inter-género e intra-género, inter-étnico e intra-étnico, (homem branco/homem negro, homem branco/mulher negra, homem negro/ mulher branca, homem negro/mulher negra).

Referindo-se a um estudo e a algumas entrevistas, o $n^{\circ} 4$ da Afro traz um artigo no qual se procura comprovar que os "Negros levam vantagem no SEXO" e recorrendo a um estudo realizado pelo sexólogo Nuno Monteiro Pereira que resultou no livro $O$ pénis - da masculinidade ao órgão masculino, em que fez a medição ao pénis de homens Portugueses e Africanos, chega à conclusão que o mito de que os homens negros/Africanos têm um pénis maior se confirma. Confirmado o mito do pénis maior confirma-se o mito de que a performance sexual dos homens Africanos é melhor do que dos homens Portugueses, nesse caso. Afirmando ainda que

\begin{abstract}
Por norma, africano que é africano gosta de se divertir, de sair, de ir para a pista e dançar...corpos bem juntos, em sintonia perfeita, que se movem ao som de uma música muito caliente. No ar sente-se o aroma de sedução que invade a "arena" onde homens e mulheres partilham uma kizomba, um dos ritmos Africanos que mais faz suspirar os corações e cuja proximidade com que se dança põe qualquer um a transpirar (Afro, 4:98).
\end{abstract}

Não podemos deixar de olhar para esse projecto de positivização em que os manejos situacionais do corpo (negro) etnicizado e estetizado podem ser também apreendidos como 
veículo de representações estereotipadas (negativizadas) e enquanto narrativas, potencialmente, encarceradoras. Assim sendo poder-se-ão juntar outras questões a essa reflexão: se é pelo corpo que africano que é africano afirma a sua identidade, o que dizer de quem se afirma africano(a) e não sabe dançar ou quem não tem ancas largas, não sabe mexer o corpo de forma caliente?

$\mathrm{O}$ que se quer notar aqui é que, no Portugal Pós-colonial, os sentidos sociais atribuídos por Africanos e não-Africanos aos manejos e performances corporais na construção de feminilidades e masculinidades diferenciadas e diferenciadoras, em contextos de comunicação intercultural e relações inter-étnicas, criam expectativas performativas, através do corpo, em torno de mulher negra e homem negro, potencialmente redutoras.

Nesse sentido, quem não se auto-define enquanto africano, pelo seu corpo, não consegue, dado os estereótipos já existentes sobre o corpo negro, fugir às expectativas dos Outros em relação a si e ao que se espera do seu corpo, pois como afirmam Reicher $e$ Koo (2004)

nossos corpos transmitem uma grande variedade de informações complexas sobre nós mesmos, com ou sem a nossa intenção, e nós e outros membros da cultura tendemos a ser peritos em ler esses significados culturalmente específicos quase que instantaneamente (Reicher e Koo, 2004:300). ${ }^{14}$

Salienta-se assim, que o corpo negro tem de ser visto enquanto construção social e por isso manejado situacionalmente, na medida em que os discursos simbólicos produzidos sobre ele são resultados da história dos encontros/confrontos entre Africanos

\footnotetext{
14 "Our bodies transmit a dizzying array of complex information about ourselves, with or without our intention, and we and other members of culture tend to be expert at reading those culturally specific meanings almost instantaneously" (Reicher e Koo, 2004:300). [tradução da autora].
} 
e Portugueses. Partindo desses discursos, ele é reapropriado, de forma positiva, num outro contexto.

Muitos são os homens, de raças que não a negra, que têm como fantasia um encontro sexual com uma bela mulata, com uma "pérola negra" - mulheres africanas - que, segundo o povo, são muito "quentes". Um dos aspectos que leva os homens a ter esse desejo tem a ver, especialmente, com a forma como as africanas se "mexem" (Afro, 4:99);

...as africanas têm no corpo a maior arma de sedução (Afro, 4:99);

Quando o assunto é "mexer as ancas", não têm dúvidas que as africanas, as mulatas $e$ as suas descendentes espalhadas pelo mundo o fazem com distinção (Afro, 4:99);

o negro tem um talento inato para o ritmo (Afro, 4:106).

Se se espera sempre que o corpo africano tenha um ritmo próprio, sobretudo pelo "mexer das ancas", pelas "danças calientes e sensuais" é porque o corpo com as suas performances tem uma importância central na criação de auto-imagens, de imagens de "nós" étnicos e dos "outros" e que potencializam relações de abertura ou fechamento antagónicas, de admiração, de imitação, de cristalização.

...muita boa gente considera os Africanos uns verdadeiros "predadores" no que toca à sexualidade. Há quem diga que os homens são mais viris e as mulheres mais sensuais quando o assunto é amor. Serão os Africanos mestres na arte do acasalamento? (Afro, 4:98).

Uma das aptidões persistentes sobre a cultura africana "é que os negros são um povo com um talento congénito para o ritmo. O movimento no rodopio e as coreografias da própria dança conferem ao corpo uma graciosidade que 
num europeu não sobressaem", explica o professor de dança de Moçambique... (Afro, 4:106-108).

As danças, por exemplo, são vistas como dinâmicas de excorporação, enquanto

práticas de exibição e ostentação pública do corpo, que materializam investimentos expressivos decorrentes de opções e decisões do sujeito, conscientemente ponderadas $e$ planeadas, relativamente aos usos que faz do corpo (Ferreira, 2007:293),

pelo que, a Afro que apresenta várias histórias e vários corpos negros, sobretudo, é assumida como o representante dos negros Africanos num contexto de relações marcadas por reivindicações em que existem situações quotidianas de invisibilidade/visibilidade negativa, de discriminação dos negros.

O corpo pós-colonial assume-se então enquanto manifesto, que exalta o seu papel enquanto corpo político, no sentido em que

muitos movimentos sociais $e$ identitários ligados a populações definidas sobretudo pela lógica da corporalidade (nomeadamente mulheres, negros, gays $e$ lésbicas, etc.) praticam política de corpo, nas suas representações e vivências (Almeida, 2004a:31).

$\mathrm{O}$ que significa que o corpo negro, que faz parte, que cria $e$ estabelece relações interpessoais, nesse caso inter-étnicas, que não pode ser excluído do encontro entre Nós e os Outros, é tido como um espaço não estático e dinâmico que transporta outras pertenças.

A Afro pode ser também percebida com uma estratégia de mudar o estado das "coisas" nas relações entre Africanos, imigrantes e Portugueses, com os quais quotidianamente dividem espaços conflituosos, espaços que na maioria das vezes são espaços de inter-etnicidade forçada, como sejam os espaços de trabalho, bairros, prédios, os media, etc. Como afirma Almeida 
(2004a:19), "A história deu as suas voltas e muitos 'pretos' pegaram nos materiais que tinham à sua disposição $e$ transformaram-nos em fontes de orgulho e identidade".

Essa questão de políticas de corpos torna-se mais enriquecedora quando por outro lado deparamos com a necessidade, como constata Inocência Mata (2006), de haver estratégias de cima para baixo, isto é, políticas do governo e do estado para que se notem quotidianamente uma "desincorporação de preconceitos, raciais e administrativos" (id.ib.:303).

Os espaços de interacção pública devem-se tornar mais "heterogéneos", no sentido em que essas políticas governamentais e da sociedade civil no geral têm de promover oportunidades para que os negros/corpos negros Africanos se tornem mais visíveis, sobretudo, em serviços que implicam atendimento ao público (id.ib.).

A desincorporação de espaços homogéneos, onde os negros não são visíveis, faz-se também pela incorporação destes num espaço público, que necessariamente deve tornar-se mais heterogéneo.

Este é também o projecto da Afro:

Há muito que o mercado português precisava de uma revista - assim - escura, quente e picante como esta, uma verdadeira raça africana. A capa, com a bela Tais, representa bem tudo o que se pode esperar do conteúdo: linda, moderna, sugestiva, actual e meio passaporte para o sucesso. A matéria sobre a educação dos filhos trouxe alguma ajuda à minha vida familiar, é que o meu filhote é café com leite, é lindo, mas já sei que vai ser uma dor de cabeça quando começar a lidar com algumas maldades sobre a raça. Confesso que com a vossa ajuda fiquei mais confiante. Mantém-te assim, que já ganhaste uma fiel amiga para toda a vida, pois gosto de ler tudo (correio das leitoras, Afro, 2:4)

\section{Questões que ficam, questões a continuar}

Em antropologia e nas suas relações interdisciplinares, somos treinados contra essencialismos e reificações que decorrem 
da análise de narrativas identitárias, produzidas em contextos de competições identitárias.

Esses treinamentos também nos obrigam, no quadro das responsabilidades sociais da antropologia, a exercer um olhar crítico sobre o projecto da revista Afro e sua longevidade, dado que esta surge num contexto em que ainda quase ou nada se fez para que a visibilidade positiva dos negros no espaço público português seja uma realidade constante. Embora se reconheça nesse projecto possibilidade de mudanças, sobretudo nas dinâmicas de poder entre os imigrantes e a sociedade portuguesa, não deixa de fazer sentido, alargar o sentido deste ensaio, com algumas reflexões:

Quando a Afro tiver feito referência aos Africanos/negros que hoje em dia o público português conhece pelos media, de que "vencedores" falarão?

Sendo a Afro uma revista pensada sobretudo para mulheres de origem africana, não deixa de ser também interessante reflectir sobre as possibilidades de consumo do estilo de vida que a ela publicita. Isto é, tendo em conta a posição de classe ocupada pela maioria das mulheres africanas em Portugal, quantas delas conseguem ter um acesso efectivo aos bens de consumo, aos estilos de vida, dos(as) "vencedores"(as) da Afro?

Por outro lado, não deixa de ser possível constatar que as práticas de consumo publicitadas nos números da Afro, embora sejam (por enquanto) restritos, têm no corpo estetizado uma tela de inscrição, na qual são visíveis as alterações nas práticas de consumo que criam alicerces para dinâmicas de reconfiguração $e$ manutenção da cultura estética trazidas dos contextos de origem.

É por haver sempre, como resultado de encontro culturais, reconfigurações/manutenções da cultura de origem, que não será exagerado afirmar que poderá constituir um jogo perverso, promover a produção e consumo da chamada "cultura africana", no contexto das relações pós-coloniais, pelo mapeamento dessa "cultura africana" exclusivamente relativo ao corpo negro e suas potencialidades sobretudo eróticas. 
Esse projecto pode constituir um perigo, no sentido em que tal mapeamento apresenta uma visão redutora e singular da diversidade que acompanha os imigrantes Africanos em Portugal. Isto é, nem todos os Africanos que se sentem Africanos têm de SABER mexer as ancas, nem têm de TER ancas, pénis, ou seios grandes, nem têm de SER africano apenas pelo seu corpo.

Os extractos seleccionados da revista, que nos dão conta das dinâmicas que informam a construção da masculinidade e feminilidade dos Africanos por oposição aos Portugueses, se apoiam em excessivo nos traços corporais (a cor, o tamanho do pénis, das ancas, dos seios, etc) que resultam de expectativas em torno de performances sexuais e demonstram o carácter redutor do modo africano e português de representar e apresentar o africano em Portugal. A Afro poder-se-á tornar num sistema de enraizamento e de legitimação dos preconceitos e estereótipos sobre Africanos e Portugueses já existentes.

Importa também salientar que é possível identificar nesse projecto estratégias de produção/mercantilização da revista, em que a Afro poderá ser também vista como uma forma de consumir o Outro. Esse consumo ocorre num contexto em que os marcadores identitários informam discursos que procuram legitimar uma suposta cultura ampla, mais ampla do que de uma nação, mais ampla do que um continente, pois ela se tornou diaspórica.

Mas essa produção/mercantilização da "cultura africana" $e$ do que "é ser africano" na Afro, materializada pelo "corpo negro", "culinária africana", "música africana", "danças africanas", servese de discursos já existentes e conhecidos tanto pelos Africanos como pelos Portugueses. A novidade, positiva e negativa, é a de que passou a existir uma revista com rostos negros.

Será interessante acompanhar, dadas as relações históricas de Portugal com os imigrantes pós-coloniais, agora vividas numa nação que reclama para si a imagem de nação não-racista, as possíveis reacções a essa abertura de possibilidade para uma maior visibilidade dos negros (ainda que de alguns negros) dentro da nação portuguesa. 
A Afro como (pre)texto

\section{Referências bibliográficas}

AlmeidA, Miguel Vale de. O manifesto do corpo. Manifesto (5), Lisboa, 2004a, pp.18-35.

. Um Mar da Cor da Terra. Lisboa, Celta Editora, $2004 b$.

. Comentários. In: SANCHES, Manuela Ribeiro. (org.) Portugal não é um país pequeno, Contar o "Império" na pós-colonialidade. Lisboa, Cotovia, 2006, pp.359-367.

BHABHA, Homi. The Location of Culture. London and New York, Routledge, 1994.

CARVALHO, Clara. Raça, género e imagem colonial: representações de mulheres nos arquivos fotográficos. In: MACHADO, José; CARVALHO, Clara e MENDES, Neusa. (org) O Visual e o Quotidiano. Lisboa, Imprensa de Ciências Sociais, 2008, pp.145-173.

CARVALHO, Francisco. O lugar dos negros na imagem de Lisboa. Sociologia, Problemas e Práticas (52), Lisboa, 2006, pp.87-108.

CASTElo, Cláudia. O modo português de estar no mundo: o lusotropicalismo e a ideologia colonial Portuguesa (1933-1961). Lisboa, Afrontamento, 1999.

CLIFFORD, James. The Predicament of Culture. Twentieth-century Ethnography, Literature and Art. Cambridge, MA, Harvard University Press, 1988.

CunHA, Isabel Ferin. (org) Media, Imigração e Minorias Étnicas. Lisboa, Observatório da Imigração, 2004.

FEATHERTONE, Mike e TURNER, Brian. Body \& Society: an introduction. Body \& Society (1), Nottingham, 1995, pp.1-12.

FERREIRA, Vitor Sérgio. Marcas que Demarcam. Corpo, tatuagem e Body Piercing em Contextos Juvenis. Dissertação de Doutoramento, Sociologia, ISCTE, Portugal, 2006.

FERREIRA, Vitor Sérgio. Politica do corpo e política da vida: a tatuagem e o body piercing como expressão corporal de uma ética da dissidência. Etnográfica (11), Lisboa, 2007, pp.291-326. 
GoffmAn, Erving. A Apresentação do Eu na Vida de Todos os Dias. Lisboa, Relógio d'Água, 1993.

HALL, Stuart. Representation: cultural representations and signifying practices. London, Sage, 1997.

HALLAN, Elizabeth e STREET, Brian Vincent. Cultural Encounters: Representing Otherness. London, Routledge, 2000.

HYAM, Ronald. Empire and Sexuality: the British Experience. Manchester, Manchester University Press, 1990.

MAFFESOLI, Michel. A física mística do corpo. Revista de Comunicação e Linguagens (10-11), Lisboa, 1990, pp.33-40.

MARGARIDO, Alfredo. A Lusofonia e os Lusófonos: Novos Mitos Portugueses. Lisboa, Edições Universitárias Lusófonas, 2000.

MATA, Inocência. Estranhos em permanência: a negociação da identidade portuguesa na pós-colonialidade. In: SANCHES, Manuela Ribeiro. (org) Portugal não é um país pequeno, contar o "império" na pós-colonialidade. Lisboa, Cotovia, 2006, pp.285-315.

MCCLINTOCK, Anne. Imperial Leather: Race, gender and sexuality in the Colonial Contest. New York and London, Routledge, 1995.

RibeIRO, António. O Corpo que Somos. Aparência, Sensualidade, Comunicação. Lisboa, Editorial Notícias, 2003.

RiBEIRO, Margarida Calafate. Uma História de Regressos, Império, Guerra Colonial e Pós-Colonialismo. Porto, Edições Afrontamento, 2004.

REICHER, Erica e KoO Kathryn. The body beautiful: Symbolism and agency in the social world. Annual Review of Anthropology (33), 2004, pp.297-317.

SANCHeS, Manuel Ribeiro. (org.) Portugal Não é um País Pequeno. Contar o 'Império' na pós-colonialidade. Lisboa, Cotovia, 2006.

SHILLING, Chris. Educating the body, physical capital and the production of social inequalities. Sociology (25), UK, 1991, pp.653-672.

. The Body and Social Theory. London, Sage Publications, 1993. 
A Afro como (pre)texto

. The body and difference. In: WoODWARD, Kathryn. (org.)

Identity and Difference. London, Sage, 1997a, pp.65-107.

. The undersocialised conception of the embodied agent in modern sociology. Sociology (31), UK, 1997b, pp.737-754.

. Embodiment, experience and theory: in defense of the sociological tradition. The Sociological Review (49), USA, 2001, pp.327-344.

STOLER, Ann Laura. Race and the education of Desire: Foucault's History of Sexuality and the Colonial Order of Things. Durham and London, Duke University Press, 1995.

Revista Afro - números consultados:

Número 1, 2008, Fevereiro

Número 2, 2008, Março

Número 3, 2008, Abril

Número 4, 2008, Maio

Número 5, 2008, Junho

Número 6, 2008, Julho - Agosto

Número 7, 2008, Setembro - Outubro 